\title{
Creative Reasoning in Solving Algebra Problems
}

\author{
Sri Hariyani \\ Mathematics Department \\ Kanjuruhan University \\ Malang, Indonesia \\ srihariyani@unikama.ac.id
}

\begin{abstract}
Students solving algebra problems in the classroom generally uses an imitative mindset. Students who have an imitative mindset will not be able to think creatively, whereas solving algebra problems requires creativity. The purpose of this study is to describe one form of creativity in solving algebra problems. Type creativity in problem solving is solving algebra problems differently. Algebra problem solving in this research use exploration, idea formation and justification stage. This research method is think alouds and semi structured interview. Researchers describe students' thinking in solving algebra problems. The results show that students who can come up with different solutions use creative reasoning. The results of the study are expected to be a contribution for teachers to design material questions that lead to the formation of creativity.
\end{abstract}

\section{Keywords-Creative, Reasoning, Solving, Problems, Algebra}

\section{INTRODUCTION}

Learning in the classroom is boring for students. That situations are less conducive to creativity growth. Teachers give problems algebra, students seek solutions algebra problems monotonically. Students work on solving algebra problems such as examples in textbooks. Students do not use reasoning to seek creative solutions. the student need to strive for reduce the complexity of problem and improve quality of problem solving [1]

A monotonous learning situation can create a comfort zone for students. A comfort zone can be a hindrance of creativity. If students are able to leave the comfort zone psychologically, mathematics will not be difficult and boring. The student tend to do the wrong thing at the wrong time in problem solving [2]. Students need to do emotional management. Emotional management is an ability to balance very low emotional frequencies with very high emotional frequency. Thus a balanced emotional management can surpass the student's comfort zone. Situations that outside of the comfort zone can foster creativity. [3] concluded that creativity is a multifaceted construct, and that different moods are differentially related to different components of creative thinking.

Creativity is the creation of something new [4]. In problem solving, solving mathematics using a different way is something new. The ways differently are shown by students is creativity, therefore students have the creativity. [5] describes creativity consists of six components. The six components of creativity are interrelated. These components include intellectual abilities, knowledge, styles of thinking, personality, motivation and environment. The three intellectual skills include (a) synthetic ability is the ability to see the problem in a new way, therefore the student must be out of the conventional boundary of thought; (b) analytic ability is the ability to distinguish between ideas that can be studied in more detail and less potential ideas; and (c) practical-contextual ability is the ability to convince others of the value of the ideas that have been obtained.

Creativity is a cognitive activity in generating a new view of a problem. Creativity is not limited to pragmatic results. Creativity is not always seen by its usefulness. Students who solve algebra problems such as teacher completion, that student is considered as an unimaginative student. Creative students always see a unique relationship between an element and another element in the problem, although the elements do not seem to be related. Creative students can come up with problem solving differently. This study describes students' thinking in solving problems differently.

Psychological theories of problem solving have largely focused on explicit processes that gradually bring the solver closer to the solution step-by-step in a mostly explicit and deliberative way [6]. The problem of algebra in this study is open ended. The algebra problem designed to enhance creative reasoning lead to a more productive problem solving. Creativity in problem solving is seen in the way of students on solving algebra problems. Creativity in problem solving is very important for students. Creativity in problem solving can make students able to think critically, logically and systematically. The results of this study are expected to be the basis for teachers to create problems that stimulate student's creativity. In addition, the results of this study are expected to help teachers design learning that can motivate the formation of creativity.

\section{METHOD}

The type of research conducted by researchers is qualitative research. This study describes student's actions in problem solving. The research was preceded by making initial observations to the school to obtain information about the level of students's mathematical understanding. All such information is used to construct the instrument. Instruments are designed to stimulate creativity of problem solving. Results of students that showing completion using different means are analyzed further.

Data were obtained through the method of think alouds and semi-structured interviews. Researchers transcribe data 
obtained from think alouds and semi-structured interviews. Researchers reviewed the results of transcripts of data, then the data was reduced. The researcher made abstraction based the data reduction. Researchers compile and coded the data according to the stages of problem solving. Problem solving using exploration, idea formation and justification stage [7]. Researchers describe students's thinking in solving algebra problems. Researchers draw conclusions about students's creative reasoning in solving algebra problems.

\section{RESULT AND DISCUSSION}

Problem solving student's activity using exploration, idea formation and justification stage [7]. Algebra problem in this research designed empirically for assessing the argumentation, creative reasoning, and problem solving.

\section{A. Result}

At the exploration stage, students understand the problem situation. The student read the sentence aloud. Students look at each part of the sentence. Students attempt to make connection between one sentence with another. Students mark a sentences. Student's marking only focuses on a few sentences that are considered important. Students also rewrote marked sentences.

Part of the problem sentence marked by the student:

Iswanto wanted the cans to be fully loaded, so Iswanto took some cans and poured the contents on the other cans. Iswanto only needs 5 cans to make the other cans full. The five empty cans were removed. The contents of each tin now adds exactly $1 / 5$ of the contents of the original can.

At the stage of idea formation, students are able to produce solutions differently. Students create illustrations of images based on marked sentences. Based on the illustration of the drawings, students make conclusions using the concept of comparison. students write " 1 cans with initial content $=5$ cans to full", If one can of soy milk can fill five cans of other soybean milk until full, then the five cans of soy milk can fill the other cans by writing "5 cans $=5 \times 5=25$ ". Students reviewed the goal to be achieved by saying, "it was reduced by 5 let the other cans be fully loaded, meaning initially it was $25+5=30$ cans", so that many cans of soy milk before the pick up was 30 cans.

At the stage of justification, students write down the steps of solving algebra problems. Students find the end result of solving algebra problems. Then, students recheck the resulting settlement. Students also develop alternative solutions.

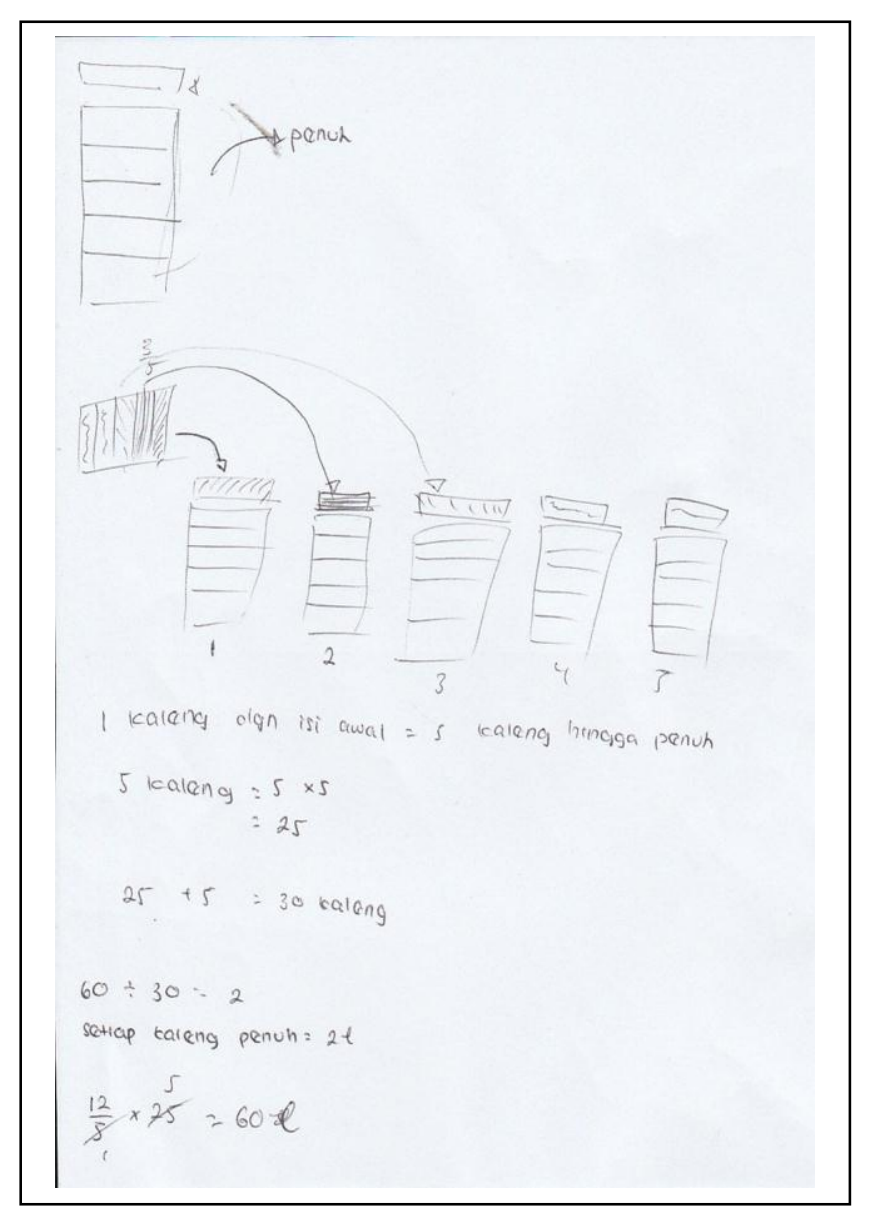

Fig. 1. Solving algebra problems by students

\section{B. Discussion}

Solving problems using different ways indicates the courage and ability to generate originality of the idea of the resulting solution. Problem solving uses a different way from a previously familiar way intended to achieve the goal [8]. The schema theory [9] shows that when the old schema is not found, the student uses the previous schemas that are identical / relevant. Students may also use different schema. Students are unable to find the old schema. This means students are unable to remember the procedural way that the previous teacher had taught. Therefore students are looking for problem solving in different ways.

[10] find that most task solutions are based on available algorithms, often without arguments that justify the reasoning, which may lead to rote learning. Solving problems differently is the result of students's reasoning. Students investigate complex issues. Mathematical reasoning is reflected in the student's critical ability to the given problem. Students are able to think critically in understanding the problem situation. Students describe problems using illustrations. The illustrations are the way students simplify the given problem. In addition, illustration is a way to develop the ability of problem solving creativity. Success in problem solving is seen in the quality of settlement methods [11]. 
Success in solving algebra problems is determined by two things, namely the understanding of the concept of algebra and the understanding of how to bring up different representations [12]. Students's creativity in eliciting different representations is facilitated through the illustration. Illustration as visual representations are used to shape students's understanding of the problem situation [13]. Different representations are also influenced by implicit processes. The implicit process in the formation of different representations is called incubation [6]. This means that students experience an implicit process in bringing up illustrations of images.

\section{CONCLUSION}

Solving algebra problems differently using three stages of problem solving. These three stages are described as follows: (1) At the exploration stage, students understand the problem statement. Students formulate information on algebra problems. Students also formulate goals to be achieved. Students make marker on sentences. Students interpret sentences. Students rephrase sentences marked using their own sentences; (2) At the stage of idea formation, students are unable to find the appropriate old schema. This means that students are not able to remember the procedural ways that teachers have taught before. To get different solutions, students use previous schemas that are identical / relevant; and (3) At the stage of justification, students get the final result of algebra problem solving. Students check the truth of the answer. Students review the problem situation. Students develop algebra problem solving with alternative solutions.

Solving problems using different ways indicates the courage and ability to generate originality of the idea of the resulting solution. Solving problems differently is the result of students's reasoning. Mathematical reasoning is reflected in the student's critical ability to the given problem.

Based on the results of this study, the researcher's suggestion for the teacher is the problem given to the student should be a problem that can make the students happy, focused and challenged to find a solution. A challenging math problem is expected to come up with creative ideas (new perspectives) to get a different way of settlement. If creative thinking becomes a habit, creative thinking can create people who dare to make breakthroughs and generate new innovations.

\section{ACKNOWLEDGMENT}

This research was conducted in the context of the completion of a research under the guidance of institution. Therefore, the researcher would like to thank to rector of Kanjuruhan University on administration contribution so that this research went easily and smoothly.

\section{REFERENCES}

[1] B. Buxton, "How to Think Outside the Box," BusinessWeek Online, 2009.

[2] J. Montier and J. Mauldin, "The Dash To Trash And The Grab For Growth," Outside the Box, 2008. .
[3] G. Lindqvist, "Vygotsky's Theory of Creativity," Creat. Res. J., 2003.

[4] “Achieving extraordinary results," Business Strategy Review. 2006.

[5] L. fang Zhang and R. J. Sternberg, "Revisiting the investment theory of creativity," Creat. Res. J., 2011.

[6] S. Helie and R. Sun, "Implicit Cognition in Problem Solving," Psychol. Probl. Solving, 2012.

[7] S. Hariyani, I. Yuwono, C. Sa 'dijah, and S. Rahardjo, "Math Problem Solving Phases on Thinking Outside The Box," IOSR J. Res. Method Educ. Ver. III, vol. 6, no. 4, pp. 2320-7388, 2016.

[8] A. Herrmann-Nehdi, "Whole Brain Thinking," $T+D, 2010$.

[9] R. Axelrod, "Schema Theory: An Information Processing Model of Perception and Cognition Schema Theory: An Information Processing Model of Perception and Cognition*," Source Am. Polit. Sci. Rev., vol. 67, no. 4, pp. 1248-1266, 1973.

[10] T. Bergqvist and J. Lithner, "Mathematical reasoning in teachers' presentations," J. Math. Behav., 2012.

[11] A. Kazakçı, T. Gillier, G. Piat, and A. Hatchuel, "Brainstorming versus creative dKazakçı, A., Gillier, T., Piat, G., \& Hatchuel, A. (2014). Brainstorming versus creative design reasoning. Design Computing and Cognition 2014, 1-20. Retrieved from http://hal-ensmp.archivesouvertes.fr/hal-00969300esign rea," Des. Comput. Cogn. 2014, pp. 120, 2014.

[12] M. K. Mielicki and J. Wiley, "Alternative Representations in Algebraic Problem Solving: When are Graphs Better Than Equations?," J. Probl. Solving, 2016.

[13] D. Zahner and J. E. Corter, "The process of probability problem solving: Use of external visual representations," Math. Think. Learn., 2010. 